\title{
BIBLIOTECA PÚBLICA DEL DISTRITO DE LATINA "ANTONIO MINGOTE". MADRID/ESPAÑA ${ }^{(*)}$
}

\section{(PUBLIC LIBRARY OF LATINA'S DISTRICT "ANTONIO MINGOTE". MADRID/SPAIN)}

Francisco Rodríguez de Partearroyo, Arquitecto

RESUMEN

La biblioteca pública "Antonio Mingote" del distrito de Latina en Madrid es un elemento más que da soporte al Plan Regional de Bibliotecas de la Comunidad de Madrid.

Se trata de un edificio que se ajusta canónicamente al esquema de biblioteca pública de distrito, con aportaciones técnicas y arquitectónicas notables, tanto por la distribución de los espacios como por las soluciones constructivas, en especial en el tratamiento de sus cerramientos exteriores.
Fecha de recepción:30-X-97

$142-160$

\section{SUMMARY}

The public library "Antonio Mingote" of Latina's district in Madrid is one element more that maintains The Regional Plan of Libraries of Comunidad de Madrid.

It is about a building that adjusts to the canon of the scheme for district's public library, with outstanding tecnical and architectural contributions, as much for the distribution of the spaces as for the constructives solutions particullarly in the treatment of its front's materials.

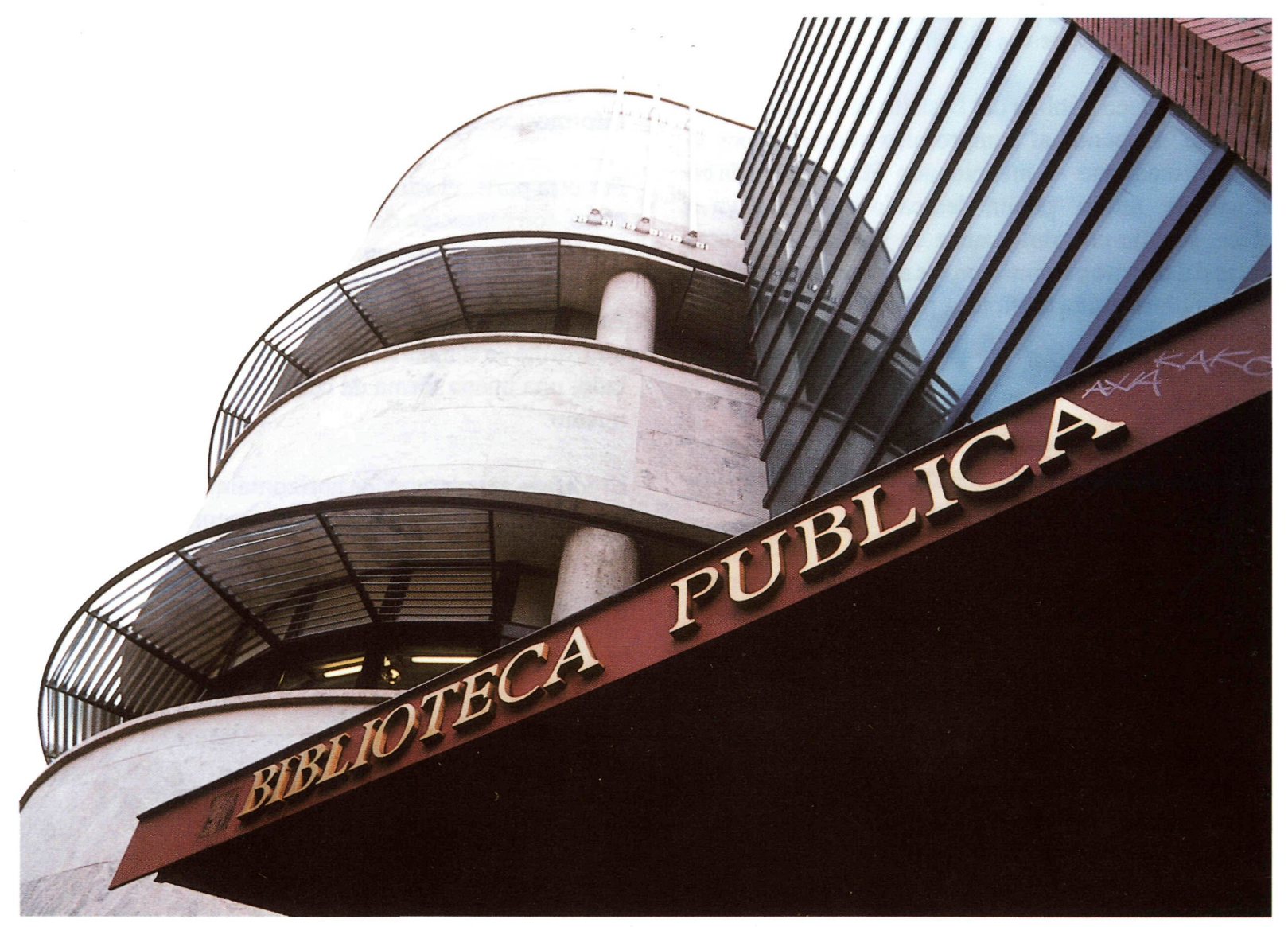

${ }^{(*)}$ Calle Rafael Finat, esquina a José Cadalso. 1989 Anteproyecto del concurso. 1990 Proyecto de ejecución. 1996 Terminación. 


\section{Programa}

La biblioteca pública se erige hoy en día, como señala la Unesco, en una institución clave para el libre acceso por parte del ciudadano, sin discriminación de ningún tipo, al conocimiento, el pensamiento, la cultura y la información.

Sin embargo, no por repetido es menos cierto que las bibliotecas públicas han sido un sector tradicionalmente olvidado por la Administración, realidad que la Comunidad de Madrid, desde su creación, y en virtud de las competencias que estatutariamente le fueron asignadas, pretende superar mediante la creación de una Red de Bibliotecas que preste servicio a todos los habitantes de nuestra Región, con las instalaciones adecuadas, los fondos bibliográficos precisos, sea cual fuere el soporte en el que se encuentren, y los medios personales necesarios en número y cualificación para la gestión de una biblioteca moderna.

Con este objetivo, se elabora el Plan Regional de Bibliotecas de la Comunidad de Madrid: $1^{\text {a }}$ Fase, Madrid Capital, aprobado por la Asamblea Regional el 20 de abril de 1989, por el que, de acuerdo con las recomendaciones de INTAMEL (International Association of Metropolitan Libraries), se prevé la creación de un sistema de bibliotecas públicas en Madrid Capital constituido por una nueva biblioteca en cada uno de sus distritos.

La nueva Biblioteca Pública del Distrito de Latina "Antonio Mingote" responde al compromiso adquirido por la Comunidad mediante el mencionado Plan. Instalada en un edificio de nueva planta dedicado en exclusiva a biblioteca, supone un gran avance en los equipamientos culturales del distrito y cuenta con los servicios que, hoy en día, son exigibles a una biblioteca pública.

\section{Servicios:}

. Préstamo de libros: colección de obras de ficción y no ficción en la que están representadas todas las materias, con distintos niveles de profundidad.

- Sala de lectura y consulta: cuenta con ciento catorce puestos de lectura y una colección representativa de obras de consulta, enciclopedias y diccionarios.

. Sección de audiovisuales: incluye un fondo de discos compactos de música de todo tipo y vídeos documentales y educativos que pueden solicitarse en préstamo o utilizar en los dieciséis puestos de audición y visionado con que cuenta la biblioteca.

Sección infantil y juvenil: concebida para que los menores de catorce años dispongan de su propio espacio en la biblioteca, ofrece una variada selección de literatura y libros de conocimientos que los niños y jóvenes pueden llevarse en préstamo o utilizar en sala.

(c) Consejo Superior de Investigaciones Científicas Licencia Creative Commons 3.0 España (by-nc)
. Hemeroteca: en sus dieciséis puestos de lectura se pueden consultar los principales diarios nacionales y extranjeros, boletines oficiales y revistas españolas y extranjeras, tanto de información general como especializadas en materias muy diversas.

. Información bibliográfica: el personal bibliotecario está, en todo momento, a la disposición del público, para orientarle sobre cualquier cuestión relacionada con esta $u$ otras bibliotecas.

. Actividades culturales: servicio esencial en la biblioteca pública moderna, el salón de actos acoge actividades gratuitas para todas las edades: conferencias, exposiciones, presentaciones de libros, talleres literarios,...

La colección bibliográfica con la que la biblioteca inicia su andadura está compuesta por 45.000 volúmenes de monografías, 45 títulos de publicaciones periódicas y 2.500 unidades de audiovisuales (discos compactos, audiolibros, vídeos y CD-ROM), estando previsto que alcance en los próximos años la cifra de 85.000 volúmenes.

\section{Memoria de arquitectura}

La idea central que nos interesó desde el principio fue la de hacer un edificio singular, original, que fijara la atención de la gente para convertirse en centro irradiador de información en el barrio.

Por otra parte, el edificio en su interior debía ser diáfano, claro, con sensación de amplitud y comprensible en su uso desde el primer momento.

Así, a partir de una malla triangular de $30^{\circ}$ conseguiamos una forma en sí misma interesante -el triángulo- $y$, por otro lado, una buena forma de control desde el baricentro del mismo.

El edificio se descompone horizontalmente en "rebanadas" que dan lugar a dos espacios claramente diferenciados: la

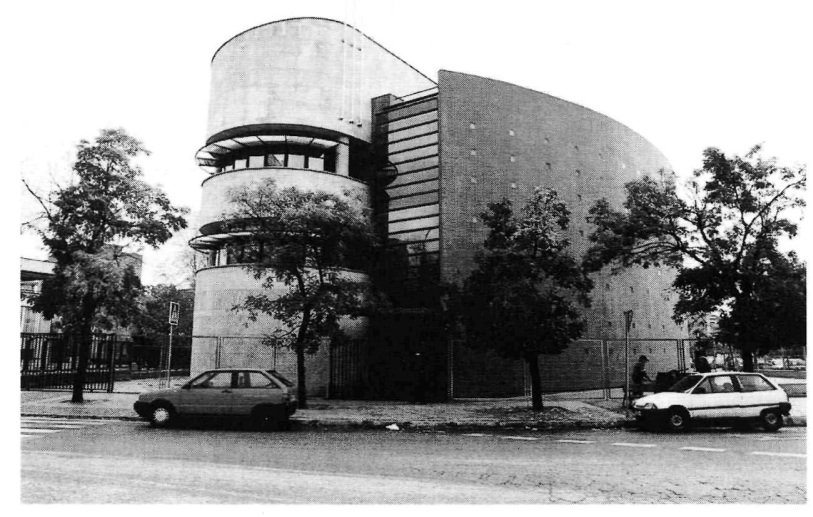

Exterior. Acceso 


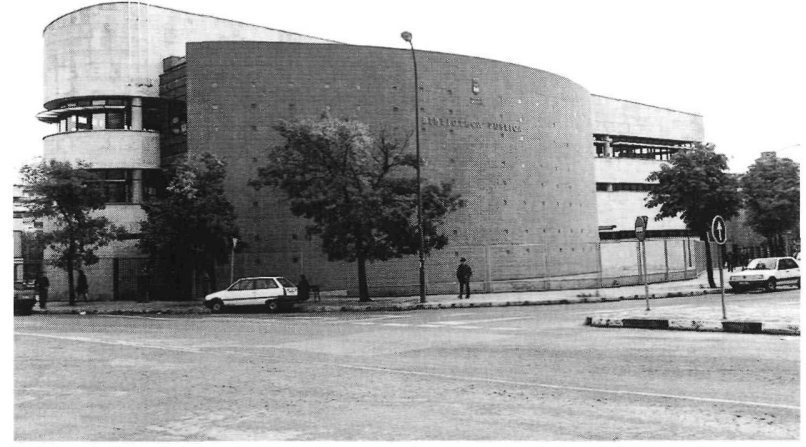

Exterior. Volumen del vestíbulo.

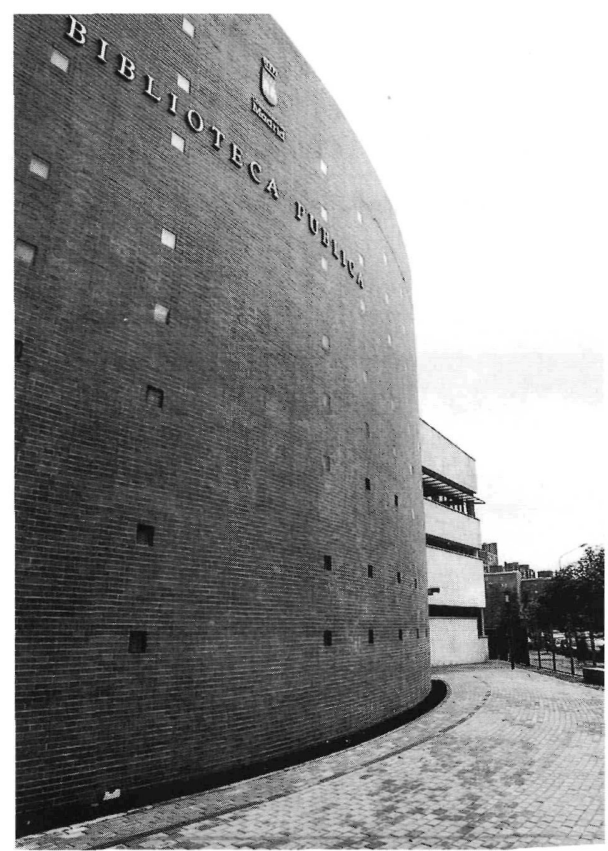

Detalle del muro de cerramiento del vestíbulo.

biblioteca infantil y la biblioteca de adultos, la primera ocupando una planta y la segunda, dos.

La biblioteca infantil tiene acceso directo a la planta baja y tienesu pequeñoestradocon gradas para representaciones o charlas.

El espacio del vestíbulo general se conforma con otra figura geométrica elemental -el arco de círculo- y supone como la palma de la mano que acoge al público que va a utilizar el edificio.

Se trata de un espacio de triple altura que incluye dos amplias escaleras y un ascensor de minusválidos y en el que se podrán contemplar las exposiciones o informaciones que disponga la dirección del centro, mediante paneles distribuidos a lo largo de los pasillos.

(c) Consejo Superior de Investigaciones Cientificas Licencia Creative Commons 3.0 España (by-nc)

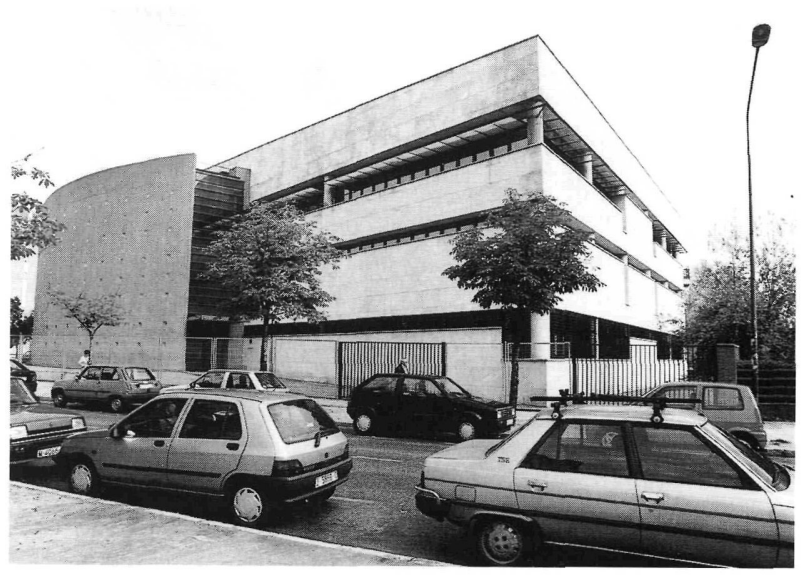

Exterior (lateral).

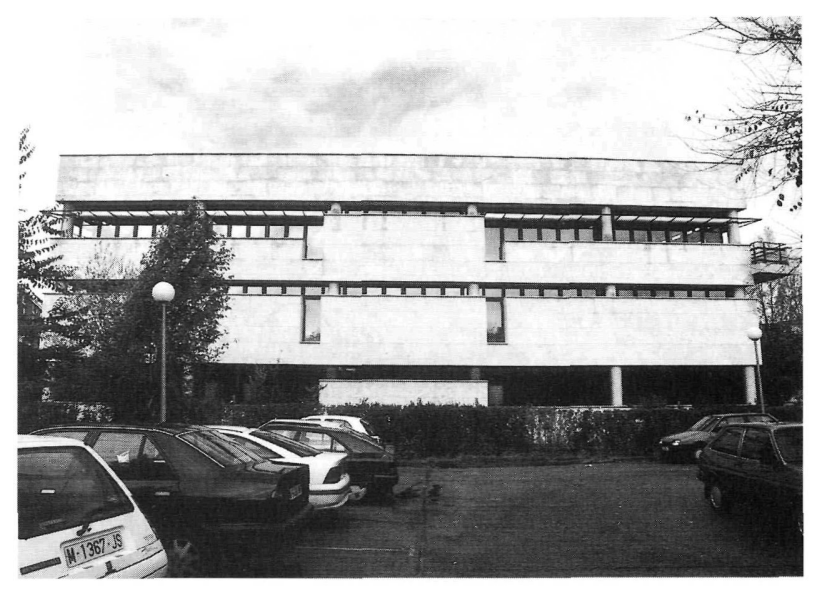

Exterior (fachada posterior).

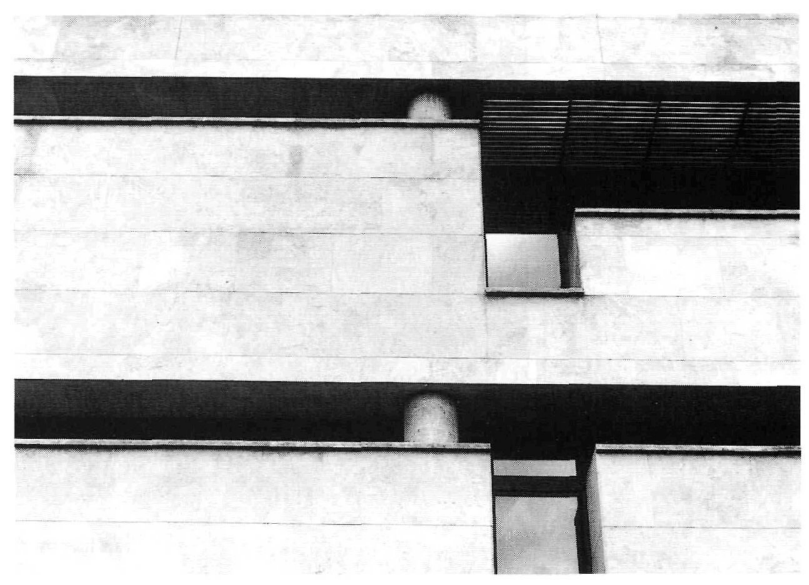

Exterior (detalles del cerramiento chapado de mármol abujardado).

Este espacio da acceso, también, a un salón de actos situado en la punta de la planta baja, que puede ser utilizado independientemente del resto de la biblioteca.

Exteriormente, el volumen del vestíbulo destaca, además, por su material, el ladrillo visto perforado por pequeños huecos cuadrados cerrados con pavés que iluminarán de 


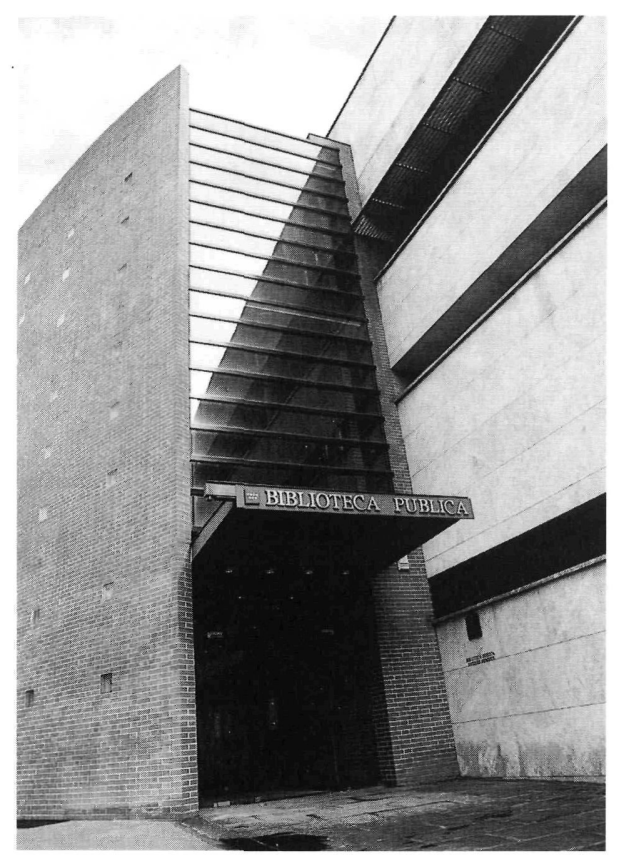

Exterior (detalle del ingreso).

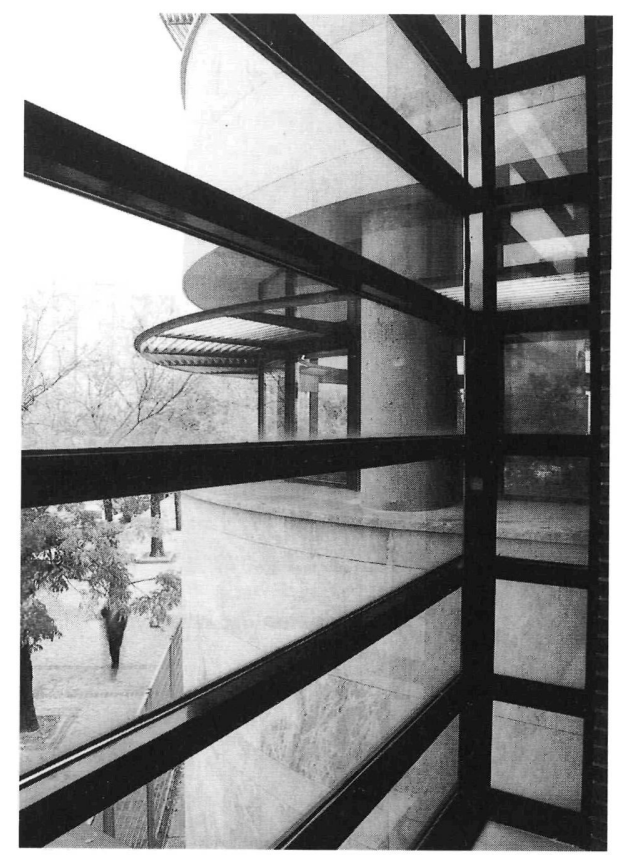

Interior (detalles de carpintería).

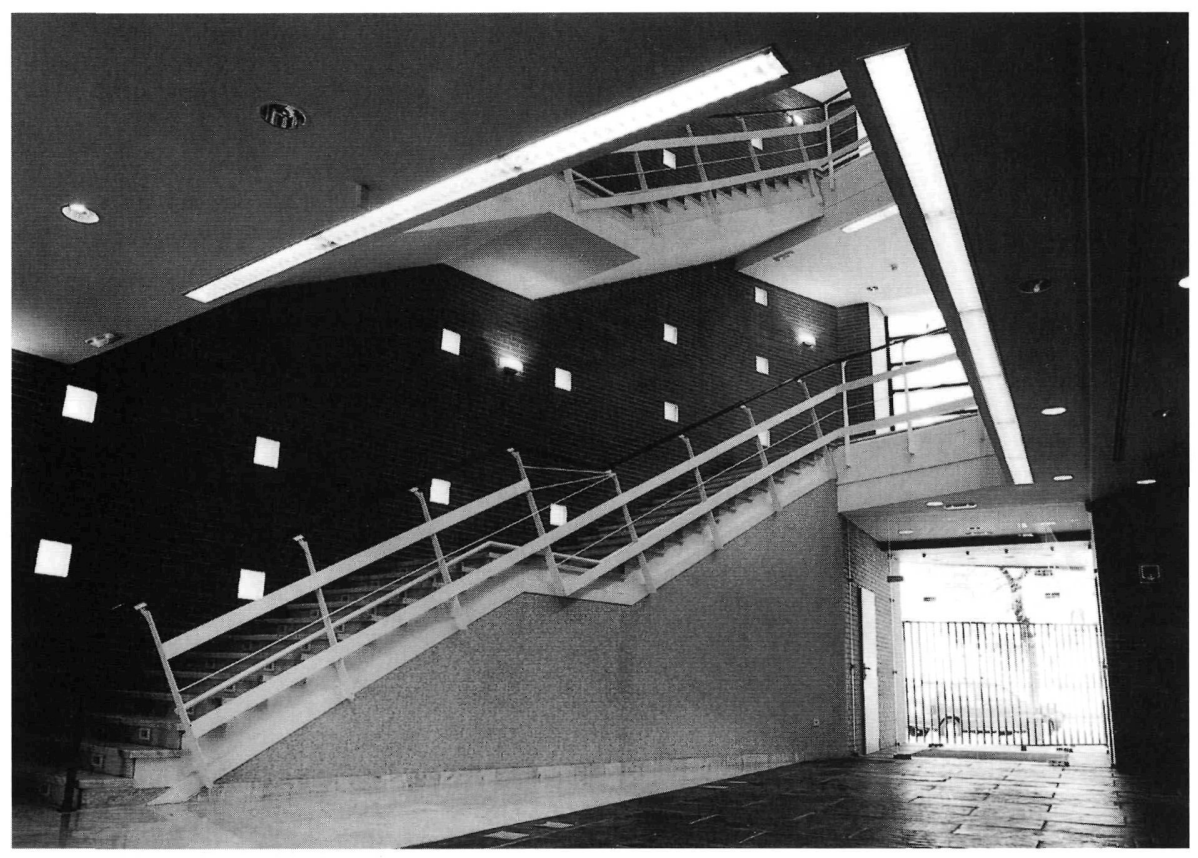

Interior (vestibulo general).

forma distinta a lo largo de las horas del día. Por la noche, esos huecos estarán iluminados por pequeñas lámparas que mantendrán la imagen de labiblioteca más allá de la puesta de sol.

El muro de ladrillo no toca al volumen triangular de la biblioteca, sino que se une mediante un nuevo material -el vidrio- materializado por un muro cortina que ilumina el espacio del vestíbulo.

(c) Consejo Superior de Investigaciones Científicas Licencia Creative Commons 3.0 España (by-nc)
El volumen de la biblioteca -convertido en una especie de nave con proa- emergiendo del volumen del vestíbulo, está chapado con mármol abujardado acentuando el despiece horizontal, que se complementa con las ventanas rasgadas horizontales que ayudan a iluminar la biblioteca uniformemente.

La biblioteca de adultos tiene acceso desde la primera planta con el control de entrada situado en el centro y con 

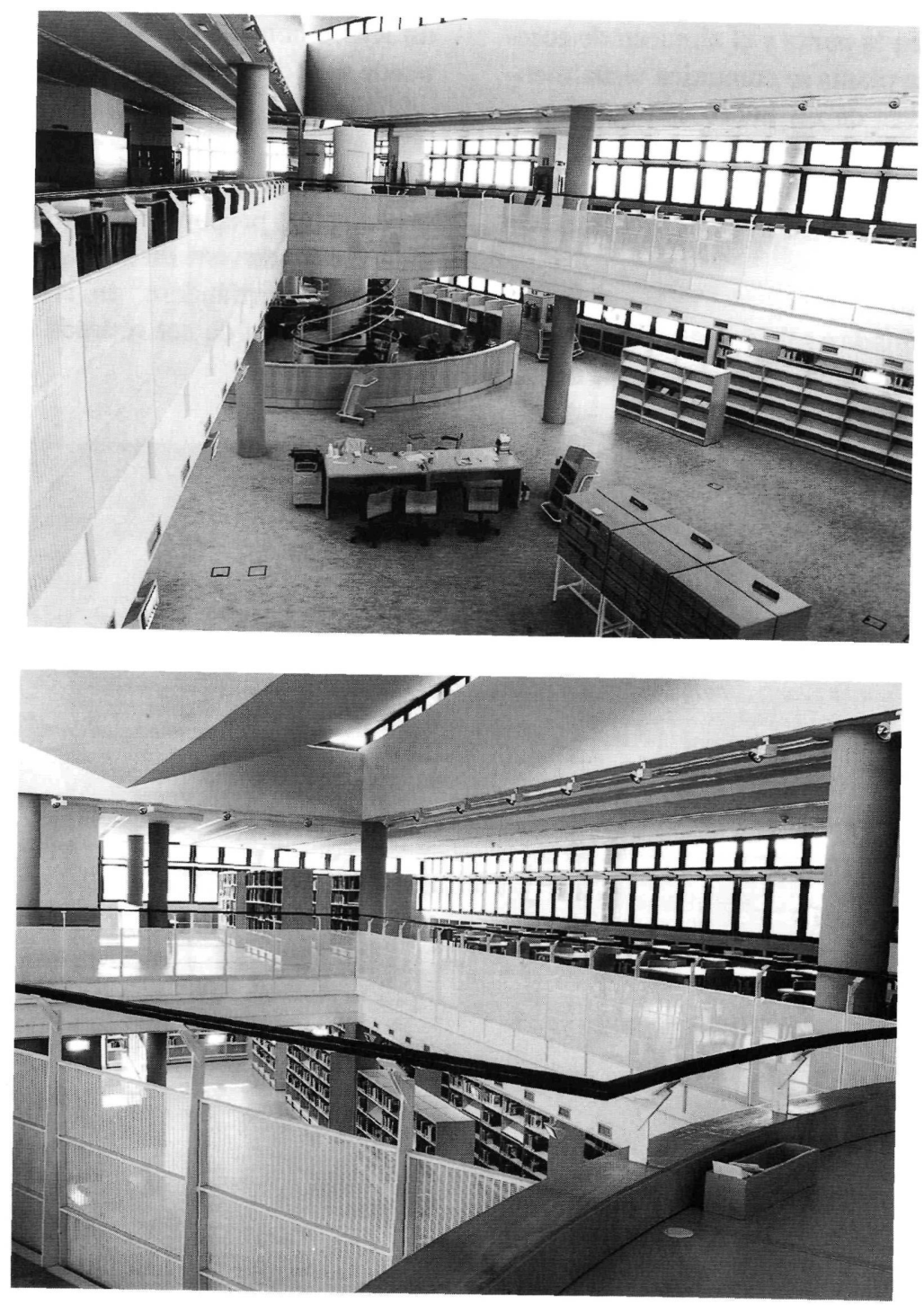

Sala de lectura.
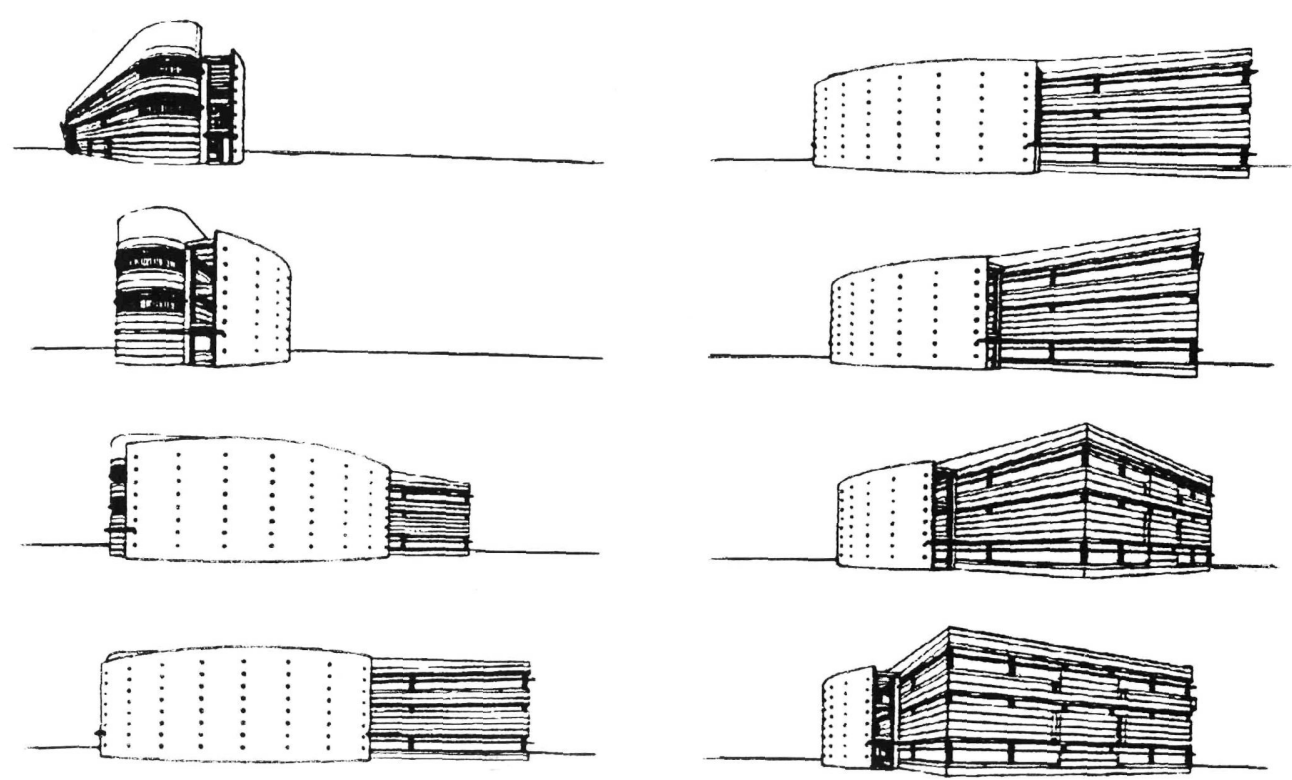

Esquema volumétrico. Visión seriada. 
las salas de hemeroteca en la punta y el almacén de acceso directo en el resto. Esta planta se comunica visualmente con la segunda a través de un hueco triangular que favorece el control centralizado y que aporta luz natural a través del lucernario inclinado -más abierto al norte, más cerrado al sur- que identifica la cubierta como una "quinta fachada" del proyecto.

A la segunda planta, destinada a sala de lectura y audición y vídeos, se accede por una escalera interior de doble tramo, un lejano homenaje a M.C. Escher. Desde esta planta se puede salir directamente al vestíbulo principal y salir del edificio.

El edificio pretende aprovechar la condición de esquina de solar, proponiendo un objeto cambiante con muchos puntos de vista distintos, negando la alineación de la calle y convirtiéndose, en cierta manera, en escultura urbana que ha de ser rodeada para ser entendida en su totalidad.
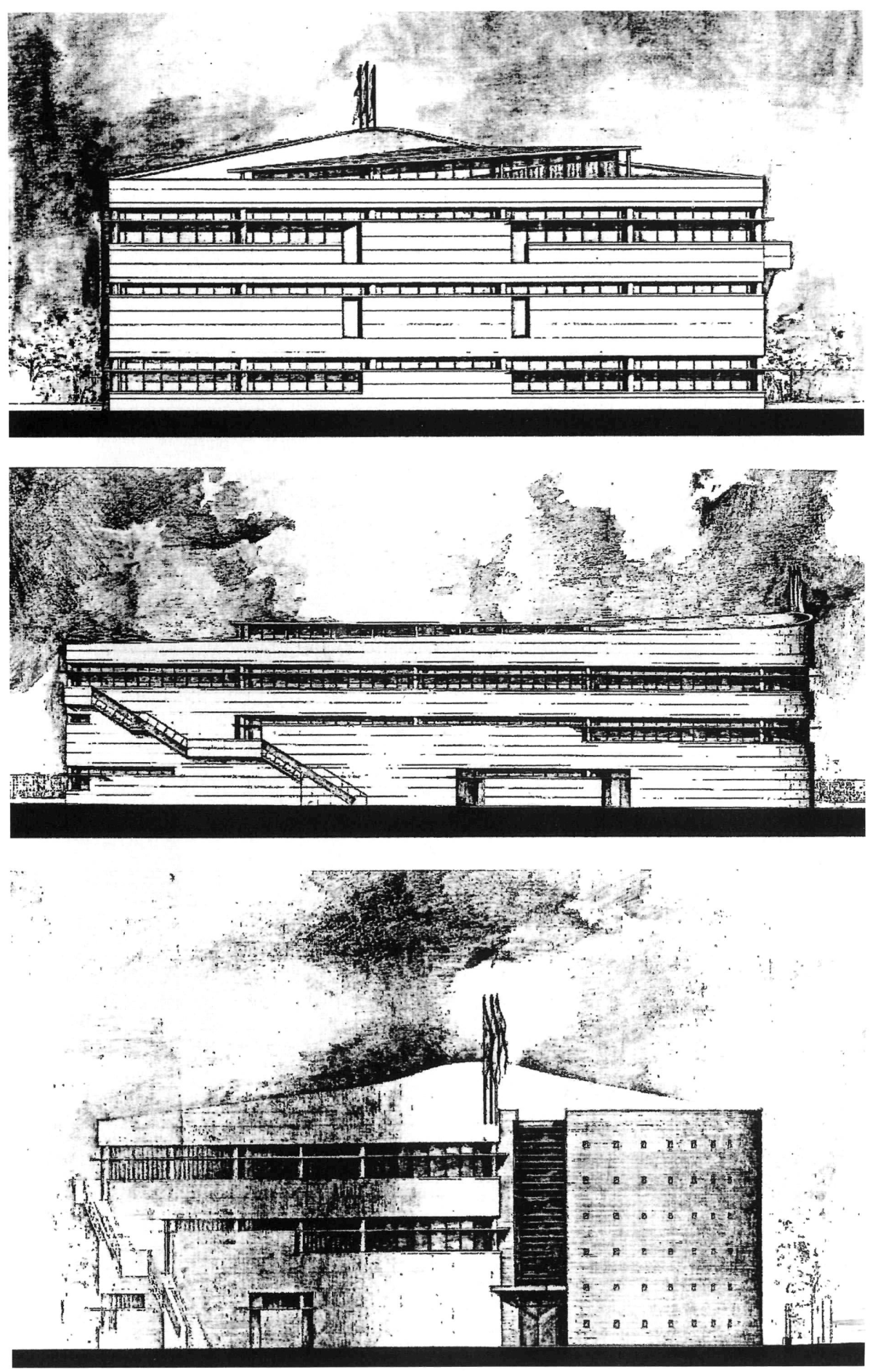


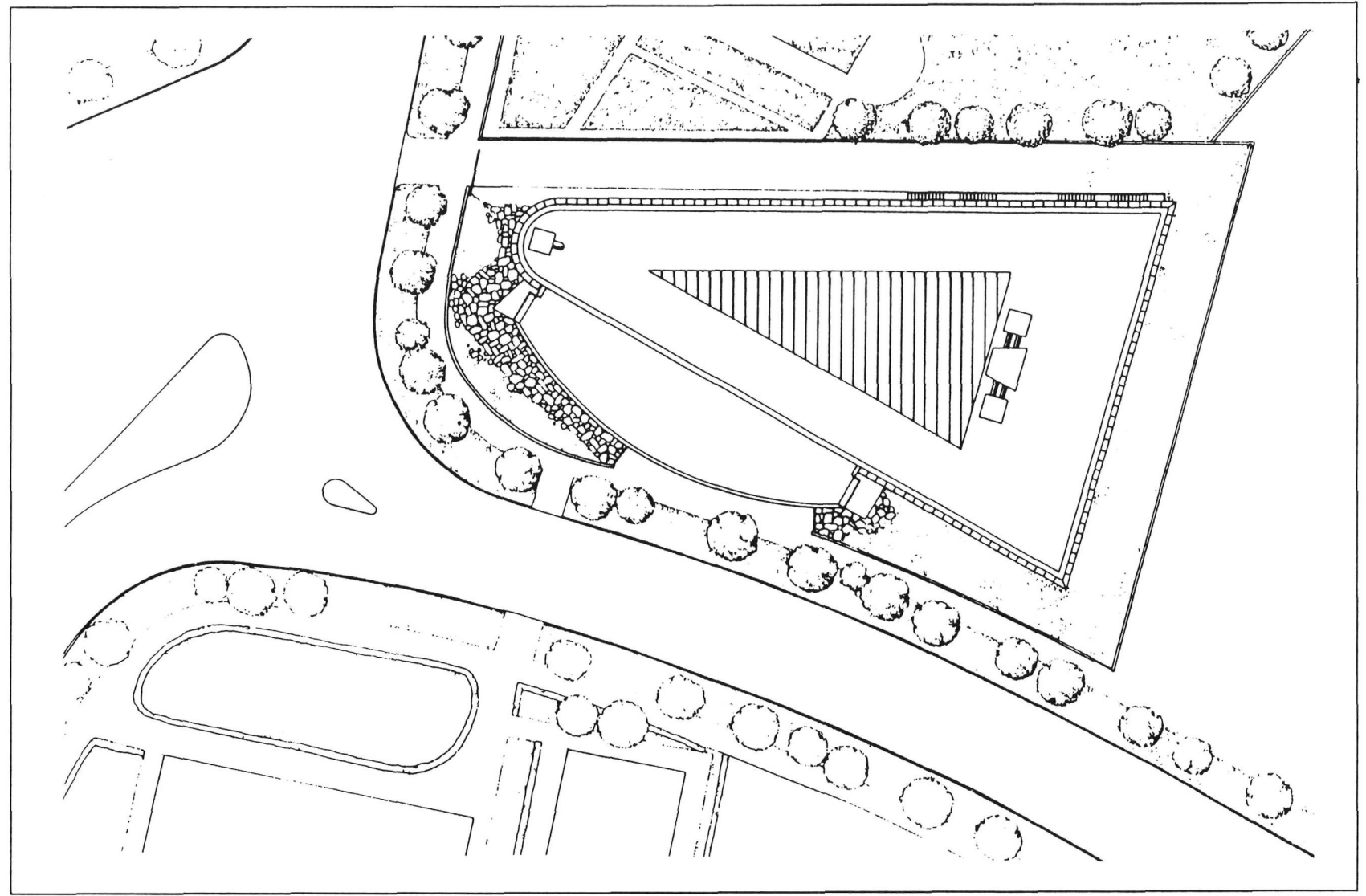

Planta de cubiertas.
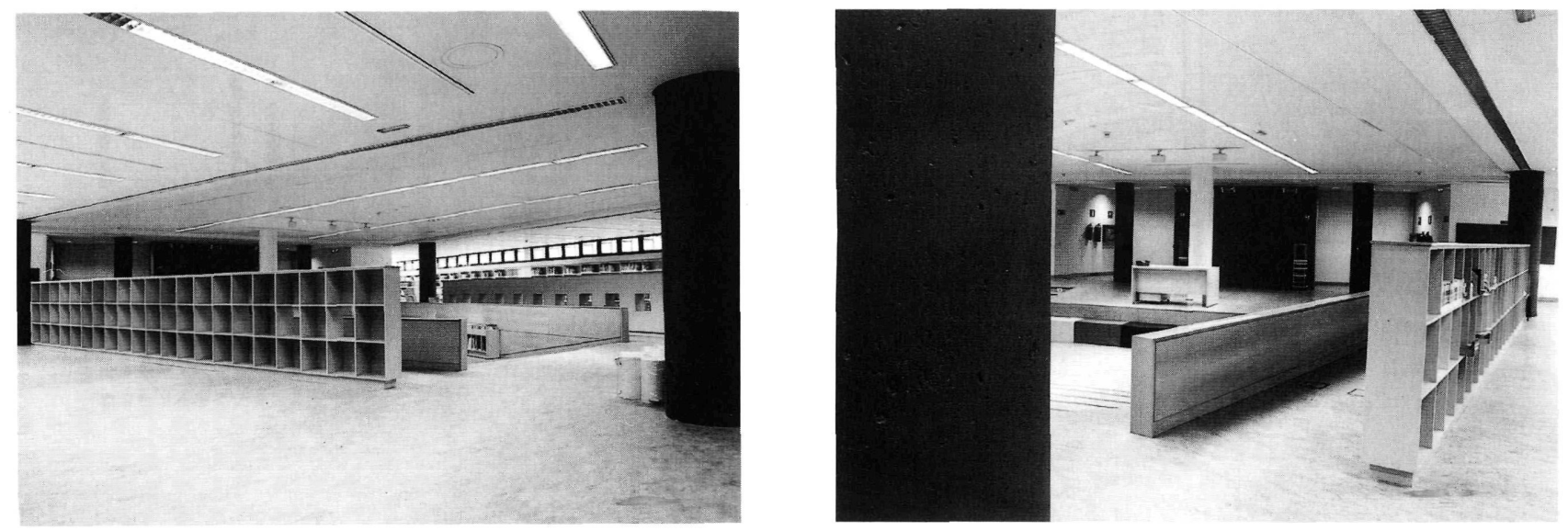

Biblioteca infantil. 


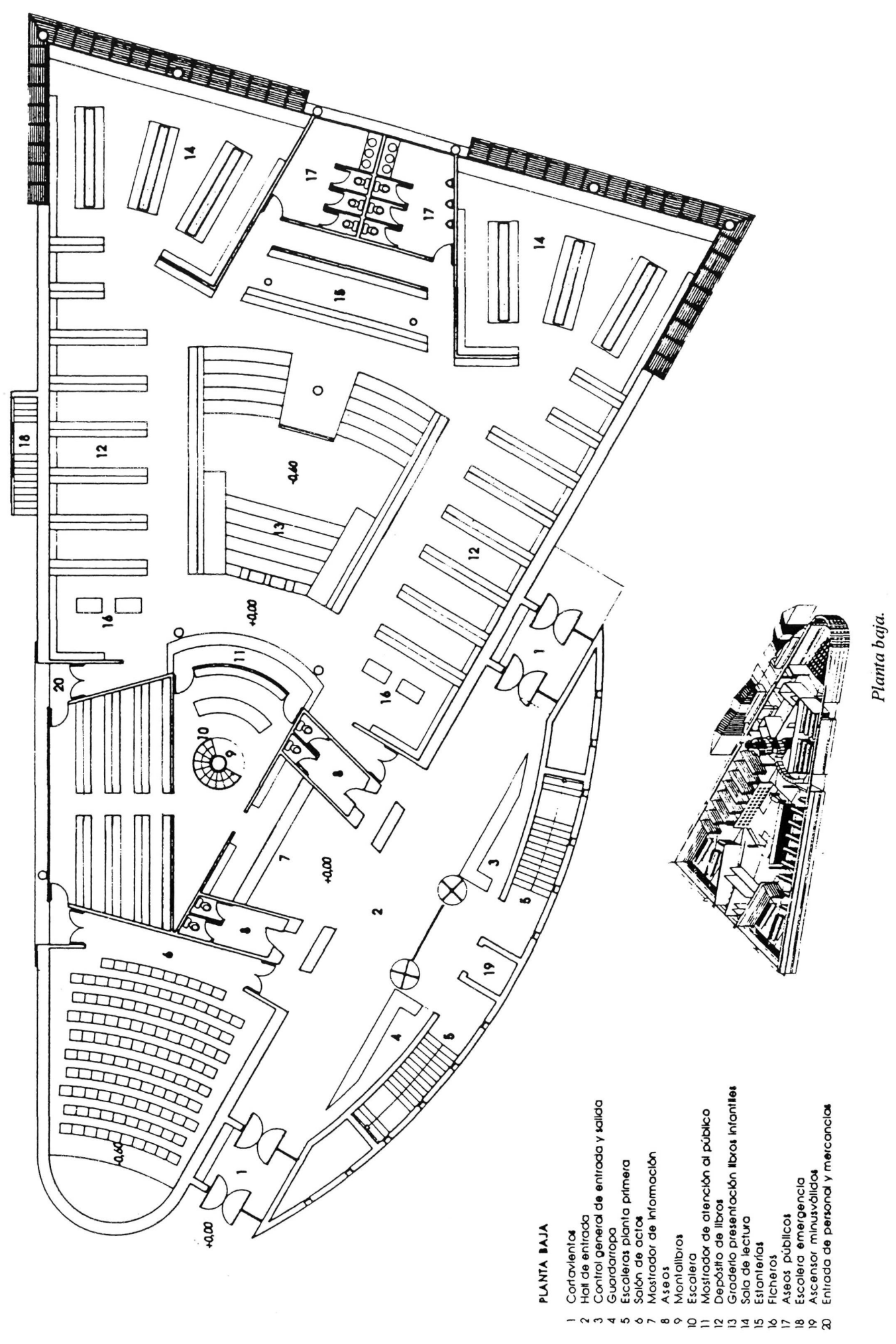




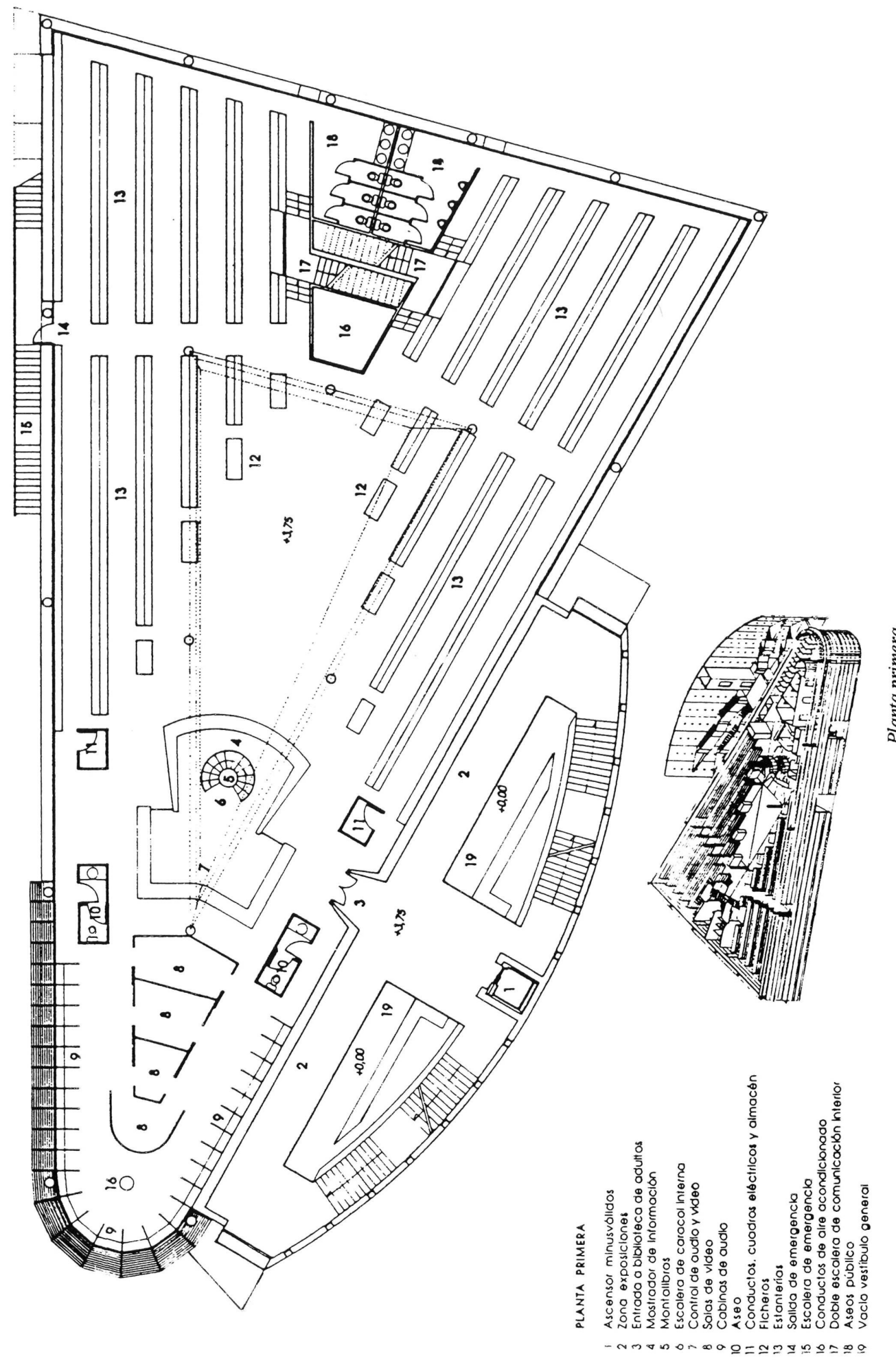




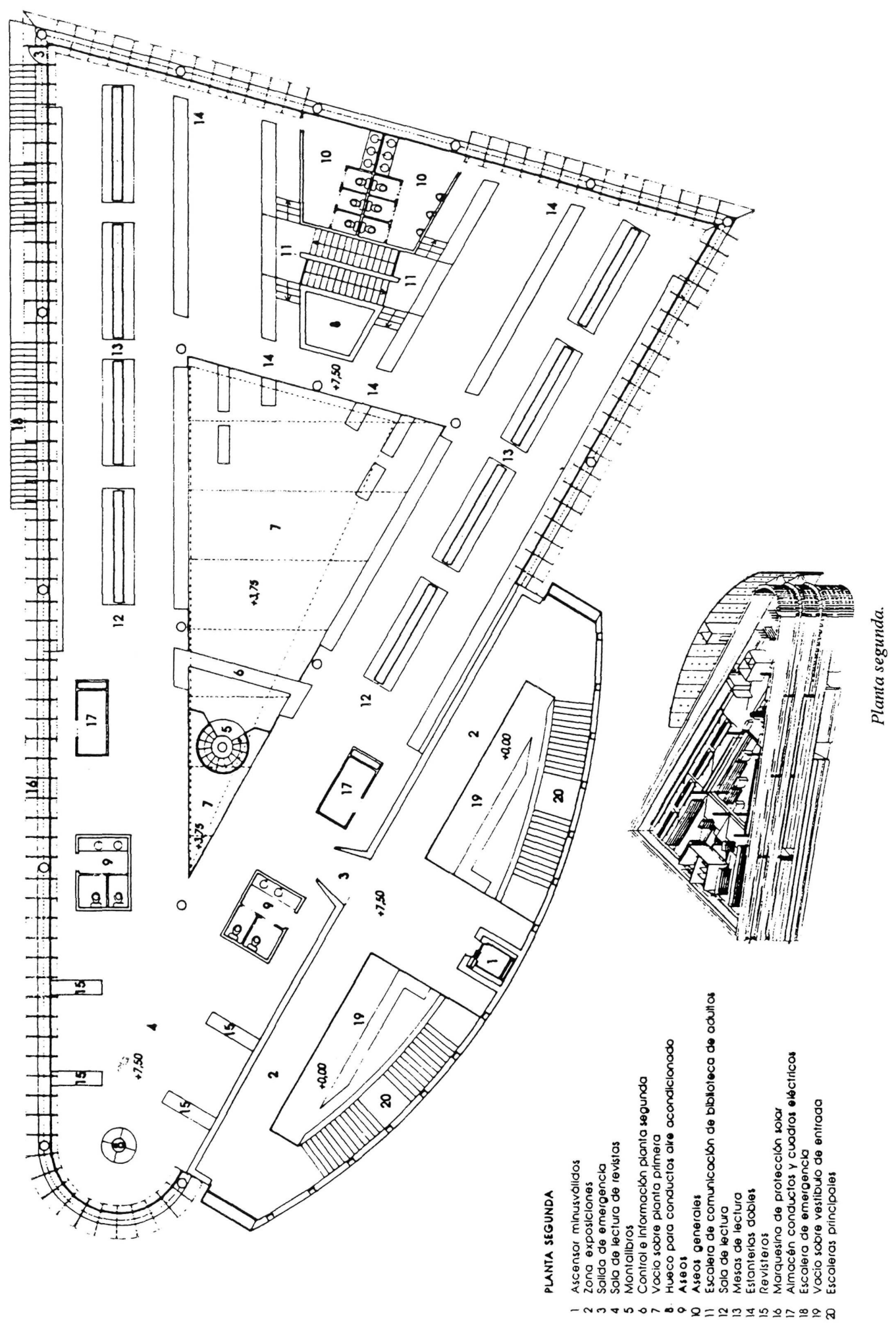




\section{Arquitecto director:}

Francisco Rodríguez Partearroyo.

\section{Arquitectos:}

David Márquez Latorre.

Ángel Martínez Díaz.

Francisco Martínez Díez.

\section{Estudiantes de Arquitectura:}

Josef Angelo Schaefer.

Klaus Hirsch.

Pilar Mateo Sánchez.

Julián Matía Sánchez.

Faustino Ocaña Vázquez.

\section{Aparejadores:}

Antonio Rodríguez Romero.

Fernando Vasco Hidalgo.

Lucinio Pérez Rodríguez.

\section{Cálculo de Estructuras:}

Alfonso Gómez Gaite, Ingeniero.

\section{Cálculo de Instalaciones:}

Manuel López Acosta, Ingeniero Industrial.

\section{Administrativa:}

María Ángeles Montes Matienzo.

\section{Publicación del Instituto Eduardo Torroja - CSIC}

Número monográfico de INFORMES
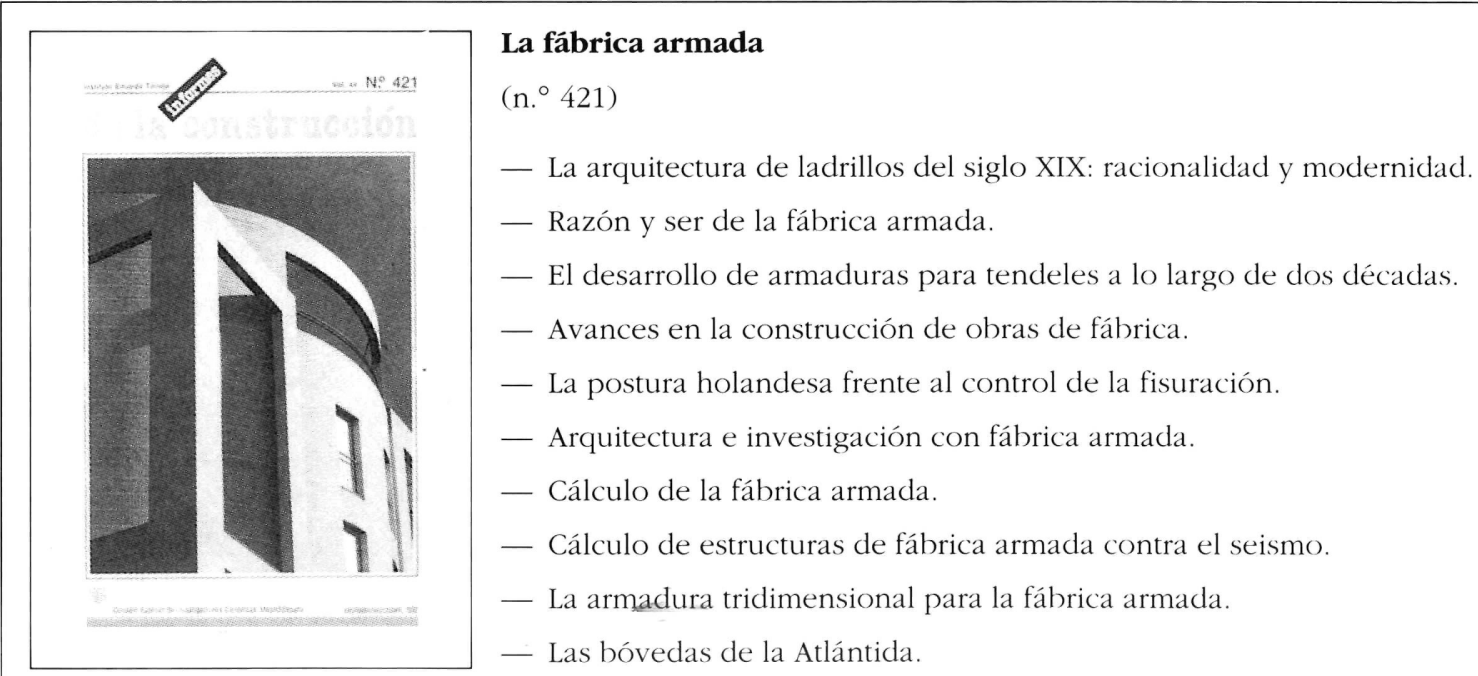